TITLE NO. 69-20

\title{
Prediction of Concrete Creep Effects Using Age-Adjusted Effective Modulus Method
}

By ZDENEK P. BAZANT

Authorized Reprint from copyrighted Journal of the American Concrete Institute April 1972, Vol. 69, p. 212-217 


\title{
Prediction of Concrete Creep Effects Using Age-Adjusted Effective Modulus Method
}

\author{
By ZDENEK P. BAZANT
}

\begin{abstract}
A recently proposed refinement of the effective modulus method, accounting for concrete aging, is formulated in a rigorous form and is extended to allow for the variation of elastic modulus and an unbounded final value of creep. A numerical example is included to show the application of the proposed method in predicting creep effects.
\end{abstract}

Keywords: age; concretes; creep properties; deflection; modulus of elasticity; prestress loss; relaxation (mechanics); shrinkage; stresses; structural analysis.

IN THE CREEP ANALYSIS OF concrete structures two kinds of errors are involved. One stems from the inaccurate knowledge of the creep law, and its minimization is a problem of materials research. The second error is caused by the simplification of analysis, which designers introduce to avoid the complexities of an exact analysis. In the sequel, only accuracy or exactitude in the latter sense will be of concern.

The simplest and the most widespread among the simplified methods of analysis is the wellknown effective modulus method, whose error with regard to the theoretically exact solution for the given creep law is known to be quite large when aging of concrete, i.e., the change of its properties with the progress of hydration, is of significance (see Table 2 discussed below). However, a surprisingly simple way of refinement of this method has been recently discovered by Trost, ${ }^{1}$ on the basis of approximate and mostly intuitive considerations. The intent of this paper is to present a rigorous formulation of this method and to extend it to the case of a variable elastic modulus and an unbounded final value of creep.

\section{FORMULATION OF METHOD}

If attention is restricted to the working stress range and strain reversals are excluded, creep of concrete may be assumed to be governed by the linear principle of superposition in time. The stress-strain relation is then fully defined by specifying functions $J_{C}\left(t, t^{\prime}\right)$ and $\varepsilon^{o}(t)$, or $E_{R}\left(t, t^{\prime}\right)$ and $\varepsilon^{o}(t)$, or $\phi\left(t, t^{\prime}\right), E(t)$ and $\varepsilon^{o}(t)$, all defined in the Appendix.

\section{Basic theorem}

Assume that:

$$
\begin{aligned}
& \varepsilon(t)-\varepsilon^{o}(t)=\varepsilon_{o}+\varepsilon_{1} \phi\left(t, t_{o}\right) \quad \text { for } t>t_{o} \\
& \sigma(t)=0 \text { for } 0<t<t_{o}
\end{aligned}
$$

where $\varepsilon_{o}$ and $\varepsilon_{1}$ are arbitrary constants.

Then $\sigma(t)$ varies linearly with $E_{R}\left(t, \mathrm{t}_{o}\right)$ and the stress-strain relations may be written (exactly) in the form of an incremental elastic law:

$$
\Delta \sigma(t)=E^{\prime \prime}\left(t, t_{o}\right)\left[\Delta \varepsilon(t)-\Delta \varepsilon^{\prime \prime}(t)\right]
$$

in which

$$
\begin{aligned}
& \Delta \varepsilon(t)=\varepsilon(t)-\varepsilon\left(t_{o}\right), \quad \Delta \sigma(t)=\sigma(t)-\sigma\left(t_{o}\right) \\
& \Delta \varepsilon^{\prime \prime}(t)=\frac{\sigma\left(t_{o}\right)}{E\left(t_{o}\right)} \phi\left(t, t_{o}\right)+\varepsilon^{o}(t)-\varepsilon^{o}\left(t_{o}\right) \\
& E^{\prime \prime}\left(t, t_{o}\right)=\frac{E\left(t_{o}\right)}{1+\chi\left(t, t_{o}\right) \phi\left(t, t_{o}\right)}
\end{aligned}
$$

$\mathrm{ACl}$ member Zdenek P. Bazant is associate professor, Department of Civil Engineering, Northwestern University, Evanston, III. Following a 3-year experience as design engineer, he received his PhD in engineering mechanics from the Czechoslovak Academy of Sciences in 1963 and the degree of Docent from the Technical University at Prague in 1967. He has held visiting appointments at CEBIP in Paris, The University of Toronto, and the University of California, Berkeley. He authored numerous papers and a book, in Czech, "Creep Analysis of Concrete Structures" and holds several patents. Currently, he is a member of $\mathrm{ACl}$ Committee 209, Creep and Shrinkage of Concrete. 
$\chi\left(t, t_{o}\right)=\left[1-\frac{E_{R}\left(t, t_{o}\right)}{E\left(t_{o}\right)}\right]^{-1}-\frac{1}{\phi\left(t, t_{o}\right)}$

where $\chi\left(t, t_{o}\right), E^{\prime \prime}\left(t, t_{o}\right)$ and $\Delta \varepsilon^{\prime \prime}(t)$ will be termed aging coefficient, age-adjusted effective modulus and fictitious inelastic strain increment.

The proof of this theorem is given in the Appendix.

\section{DISCUSSION AND APPLICATION}

Determination of $\chi$ requires the knowledge of the relaxation function, which can be obtained from the creep function $J_{c}\left(t, t^{\prime}\right)$ with the help of a computer (using the well-known numerical methods for Volterra's integral equations; see Appendix). Table 1 shows the values of $\chi$ which have been found for the following material properties:

$\phi\left(t, t^{\prime}\right)=\phi_{u}\left(t^{\prime}\right)\left(t-t^{\prime}\right)^{0.6} /\left[10+\left(t-t^{\prime}\right)^{0.6}\right]$

or

$$
\phi\left(t, t^{\prime}\right)=\phi_{u}\left(t^{\prime}\right) 0.113 \ln \left(1+t-t^{\prime}\right)
$$

where

$$
\left.\begin{array}{c}
E\left(t^{\prime}\right)=E(28)\left[t^{\prime} /\left(4+0.85 t^{\prime}\right)\right]^{1 / 2} \\
\phi_{u}\left(t^{\prime}\right)=\phi(\infty, 7) 1.25 t^{\prime-0.118}
\end{array}\right\}
$$

$t^{\prime}$ being given in days.
Eq. (7) with Eq. (9) has been recently recommended by ACI Committee 209, ${ }^{2}$ along with a method of determination of the constant $\phi(\infty, 7)$. It is acceptable for structures of typical dimensions that are exposed to a mild climate and allowed to dry. Eq. (8) is suitable for mass concrete.

Eq. (2) has the form of Hooke's law and reduces thus the creep problem to a single elastic analysis, as in the usual effective modulus method. The values of $E^{\prime \prime}$ and $\chi$ are independent of $\varepsilon_{o}$ and $\varepsilon_{1}$ and have thus the same values for any strain history which is linear with creep coefficient $\phi\left(t, t_{o}\right)$ and admits a sudden strain increment at the instant of first loading. This finding is useful because in most practical creep problems the variation of strain falls into the above category. If the load changes instantly at times after the time of first loading, the method can be also applied. The load history must then be considered as a sum of several step functions whose effects are analyzed separately and finally superimposed.

For the purpose of comparison, the $\chi$ values have also been computed for creep functions Eq. (7) and (8) with a constant modulus $E$ (Table 1 ). Obviously, the effect of the time variation of $E$, neglected in References $1,3,4,5$, is quite significant. A plot of $\chi$ shown in Fig. 1 has further been computed for the creep function recommended by CEB. ${ }^{1,3}$ It is also noteworthy (Fig. 1) that the

TABLE I - AGING COEFFICIENT $\chi$ FOR TWO DIFFERENT CREEP LAWS, WITH AND WITHOUT CONSIDERATION OF VARIATION OF ELASTIC MODULUS

\begin{tabular}{|c|c|c|c|c|c|c|c|c|c|c|c|}
\hline \multirow{3}{*}{$\begin{array}{l}\text { Creep } \\
\text { law }\end{array}$} & \multirow{3}{*}{$\begin{array}{c}t-t_{0} \\
\text { days }\end{array}$} & \multirow[b]{3}{*}{$\phi(\infty, 7)$} & \multicolumn{4}{|c|}{ Variable $E$, Eq. (9) } & \multicolumn{4}{|c|}{ Constant $E$} & \multirow{3}{*}{$\frac{\phi\left(t, t_{o}\right)}{\phi u\left(t_{o}\right)}$} \\
\hline & & & \multicolumn{4}{|c|}{$t_{0}$, days } & \multicolumn{4}{|c|}{$t_{o}$, days } & \\
\hline & & & $10^{1}$ & $10^{2}$ & $10^{3}$ & $10^{4}$ & $10^{1}$ & $10^{2}$ & $10^{3}$ & $10^{-4}$ & \\
\hline \multirow{4}{*}{$\begin{array}{l}\text { Eq. } \\
(7) \\
\text { and } \\
(9)\end{array}$} & $110^{1}$ & $\begin{array}{l}0.5 \\
1.5 \\
2.5 \\
3.5 \\
\end{array}$ & $\begin{array}{l}0.525 \\
0.720 \\
0.774 \\
0.806\end{array}$ & $\begin{array}{l}0.804 \\
0.826 \\
0.842 \\
0.856\end{array}$ & $\begin{array}{l}0.811 \\
0.825 \\
0.837 \\
0.848\end{array}$ & $\begin{array}{l}0.809 \\
0.820 \\
0.830 \\
0.839\end{array}$ & $\begin{array}{l}0.798 \\
0.820 \\
0.839 \\
0.855\end{array}$ & $\begin{array}{l}0.811 \\
0.829 \\
0.844 \\
0.857\end{array}$ & $\begin{array}{l}0.811 \\
0.825 \\
0.837 \\
0.848\end{array}$ & $\begin{array}{l}0.809 \\
0.820 \\
0.830 \\
0.839\end{array}$ & 0.273 \\
\hline & $10^{2}$ & $\begin{array}{l}0.5 \\
1.5 \\
2.5 \\
3.5 \\
\end{array}$ & $\begin{array}{l}0.505 \\
0.739 \\
0.804 \\
0.839\end{array}$ & $\begin{array}{l}0.888 \\
0.919 \\
0.935 \\
0.946\end{array}$ & $\begin{array}{l}0.916 \\
0.932 \\
0.943 \\
0.951\end{array}$ & $\begin{array}{l}0.915 \\
0.928 \\
0.938 \\
0.946\end{array}$ & $\begin{array}{l}0.848 \\
0.878 \\
0.899 \\
0.914\end{array}$ & $\begin{array}{l}0.905 \\
0.926 \\
0.939 \\
0.949\end{array}$ & $\begin{array}{l}0.916 \\
0.932 \\
0.943 \\
0.951\end{array}$ & $\begin{array}{l}0.915 \\
0.928 \\
0.938 \\
0.946\end{array}$ & 0.608 \\
\hline & $10^{3}$ & $\begin{array}{l}0.5 \\
1.5 \\
2.5 \\
3.5\end{array}$ & $\begin{array}{l}0.511 \\
0.732 \\
0.795 \\
0.830\end{array}$ & $\begin{array}{l}0.912 \\
0.943 \\
0.956 \\
0.964\end{array}$ & $\begin{array}{l}0.973 \\
0.981 \\
0.985 \\
0.987\end{array}$ & $\begin{array}{l}0.981 \\
0.985 \\
0.988 \\
0.990\end{array}$ & $\begin{array}{l}0.846 \\
0.878 \\
0.899 \\
0.914\end{array}$ & $\begin{array}{l}0.937 \\
0.953 \\
0.963 \\
0.969\end{array}$ & $\begin{array}{l}0.974 \\
0.981 \\
0.985 \\
0.987\end{array}$ & $\begin{array}{l}0.981 \\
0.985 \\
0.988 \\
0.990\end{array}$ & 0.857 \\
\hline & $10^{4}$ & $\begin{array}{l}0.5 \\
1.5 \\
2.5 \\
3.5 \\
\end{array}$ & $\begin{array}{l}0.501 \\
0.717 \\
0.781 \\
0.818 \\
\end{array}$ & $\begin{array}{l}0.899 \\
0.934 \\
0.949 \\
0.958\end{array}$ & $\begin{array}{l}0.976 \\
0.983 \\
0.986 \\
0.989\end{array}$ & $\begin{array}{l}0.994 \\
0.995 \\
0.996 \\
0.997\end{array}$ & $\begin{array}{l}0.828 \\
0.863 \\
0.887 \\
0.903\end{array}$ & $\begin{array}{l}0.927 \\
0.945 \\
0.956 \\
0.963\end{array}$ & $\begin{array}{l}0.977 \\
0.983 \\
0.987 \\
0.989\end{array}$ & $\begin{array}{l}0.994 \\
0.995 \\
0.996 \\
0.997\end{array}$ & 0.954 \\
\hline \multirow{4}{*}{$\begin{array}{l}\text { Eq. } \\
(8) \\
\text { and } \\
(9)\end{array}$} & $10^{1}$ & $\begin{array}{l}0.5 \\
1.5 \\
2.5 \\
3.5\end{array}$ & $\begin{array}{l}0.522 \\
0.727 \\
0.783 \\
0.815\end{array}$ & $\begin{array}{l}0.815 \\
0.838 \\
0.854 \\
0.867\end{array}$ & $\begin{array}{l}0.822 \\
0.836 \\
0.849 \\
0.860\end{array}$ & $\begin{array}{l}0.821 \\
0.832 \\
0.842 \\
0.851\end{array}$ & $\begin{array}{l}0.809 \\
0.831 \\
0.850 \\
0.865\end{array}$ & $\begin{array}{l}0.823 \\
0.840 \\
0.855 \\
0.868\end{array}$ & $\begin{array}{l}0.822 \\
0.836 \\
0.849 \\
0.860\end{array}$ & $\begin{array}{l}0.821 \\
0.832 \\
0.842 \\
0.851\end{array}$ & 0.269 \\
\hline & $10^{\circ}$ & $\begin{array}{l}0.5 \\
1.5 \\
2.5 \\
3.5 \\
\end{array}$ & $\begin{array}{l}0.493 \\
0.742 \\
0.807 \\
0.842 \\
\end{array}$ & $\begin{array}{l}0.901 \\
0.928 \\
0.941 \\
0.950\end{array}$ & $\begin{array}{l}0.929 \\
0.941 \\
0.950 \\
0.956\end{array}$ & $\begin{array}{l}0.929 \\
0.939 \\
0.947 \\
0.952 \\
\end{array}$ & $\begin{array}{l}0.864 \\
0.889 \\
0.906 \\
0.919\end{array}$ & $\begin{array}{l}0.919 \\
0.935 \\
0.945 \\
0.953\end{array}$ & $\begin{array}{l}0.930 \\
0.941 \\
0.950 \\
0.956\end{array}$ & $\begin{array}{l}0.929 \\
0.939 \\
0.947 \\
0.952\end{array}$ & 0.518 \\
\hline & $10^{3}$ & $\begin{array}{l}0.5 \\
1.5 \\
2.5 \\
3.5\end{array}$ & $\begin{array}{l}0.461 \\
0.702 \\
0.770 \\
0.808\end{array}$ & $\begin{array}{l}0.887 \\
0.924 \\
0.940 \\
0.950\end{array}$ & $\begin{array}{l}0.956 \\
0.966 \\
0.972 \\
0.977\end{array}$ & $\begin{array}{l}0.965 \\
0.972 \\
0.976 \\
0.980\end{array}$ & $\begin{array}{l}0.826 \\
0.859 \\
0.882 \\
0.898\end{array}$ & $\begin{array}{l}0.917 \\
0.935 \\
0.947 \\
0.955\end{array}$ & $\begin{array}{l}0.957 \\
0.966 \\
0.973 \\
0.977\end{array}$ & $\begin{array}{l}0.965 \\
0.979 \\
0.976 \\
0.980\end{array}$ & 0.775 \\
\hline & $10^{4}$ & $\begin{array}{l}0.5 \\
1.5 \\
2.5 \\
3.5\end{array}$ & $\begin{array}{l}0.434 \\
0.657 \\
0.727 \\
0.768\end{array}$ & $\begin{array}{l}0.838 \\
0.887 \\
0.969 \\
0.924\end{array}$ & $\begin{array}{l}0.940 \\
0.955 \\
0.964 \\
0.970\end{array}$ & $\begin{array}{l}0.972 \\
0.979 \\
0.983 \\
0.985\end{array}$ & $\begin{array}{l}0.767 \\
0.811 \\
0.841 \\
0.863\end{array}$ & $\begin{array}{l}0.873 \\
0.901 \\
0.919 \\
0.932\end{array}$ & $\begin{array}{l}0.942 \\
0.956 \\
0.964 \\
0.970\end{array}$ & $\begin{array}{l}0.979 \\
0.979 \\
0.983 \\
0.985\end{array}$ & 1.034 \\
\hline \multicolumn{2}{|c|}{$\begin{array}{l}\phi_{u}\left(t_{0}\right) / \phi_{u}(7) \\
E\left(t_{0}\right) / E(28)\end{array}$} & & $\begin{array}{l}0.960 \\
0.895\end{array}$ & $\begin{array}{l}0.731 \\
1.060\end{array}$ & $\begin{array}{l}0.558 \\
1.083\end{array}$ & $\begin{array}{l}0.425 \\
1.089\end{array}$ & $\begin{array}{l}0.960 \\
1.000\end{array}$ & $\begin{array}{l}0.731 \\
1.000\end{array}$ & $\begin{array}{l}0.558 \\
1.000\end{array}$ & $\begin{array}{l}0.425 \\
1.000\end{array}$ & \\
\hline
\end{tabular}
(SYMBOLS DEFINED IN APPENDIX) 




Fig. I - Diagram of aging coefficient $\chi\left(t, t_{0}\right)$ at $t-t_{0}$ $=10^{4}$ days and various times of loading $t_{0}$ for CEB creep function ${ }^{1}$, with and without consideration of variation of $E$

plots of $\chi$ versus $\log t_{o}$ are not straight lines, contrary to the previously held opinion, ${ }^{1}$ and exact values of $\chi$ considerably differ from the values determined previously by an approximate analysis $^{1,3}$ (even when the variation of $E$ is neglected). Furthermore, again in contrast with the previous opinion, ${ }^{1}$ the dependence of $\chi$ on $t$ is not always negligible, as is seen from Table 1 , and there is no reason for the $\chi$ values to be always greater than 0.5 , as Table 1 corroborates. It should be also noted that, according to the above theorem, it is not necessary to make the assumption that the final value of creep coefficient, $\phi\left(\infty, t_{o}\right)$, is bounded (which was implied in previous work $\mathbf{k}^{\mathbf{1}}$ ).

The classical effective modulus method, which is equivalent to the case $\chi=1$, is known to give very accurate results for a nonaging material. This is confirmed by Table 1 which shows that $\chi \approx 1$ for large $t_{o}$ and large $t-t_{o}$. The correction introduced by $\chi$ into the effective modulus is thus due mainly to aging of the material rather than relaxation. For this reason the term "aging coefficient" is preferable over the term "relaxation coefficient" which was introduced in previous studies. ${ }^{1,3,4,5}$
While all the other simplified practical methods, such as the effective modulus method or the rateof-creep method, give an exact solution only when $\sigma$ is constant or $\varepsilon=\varepsilon_{o}\left[1+\phi\left(t, t_{o}\right)\right]$, the present method gives an exact solution in infinitely many special cases, and especially in three basic, diametrically different cases, namely the case of constant $\sigma$ (as in the creep test), the case of constant $\varepsilon$ (as in the stress relaxation test; see Table 2 discussed below); and the case $\varepsilon=\varepsilon_{1} \phi\left(t, t_{o}\right)$ (which approximately applies to straining of a structure by differential creep). Most other strain histories represent some kind of intermediate situation between the above cases, and so the solution must usually be much closer to the exact solution than with other simplified methods which coincide with the exact solution only in one special case.

\section{NUMERICAL EXAMPLES}

The relatively lowest accuracy is to be expected when strain $\varepsilon(t)$ is prescribed as a function which considerably differs from linear dependence on $\phi\left(t, t_{0}\right)$. This occurs especially in the problem of internal forces due to shrinkage, and therefore this case will be selected for a numerical example. The unrestrained shrinkage strain for drying exposure at $t_{o}=7$ days will be assumed as recommended by ACI Committee 209: ${ }^{2}$

$$
\varepsilon_{s h}(t)=8 \times 10^{-4}(t-7) /[35+(t-7)]
$$

where $t$ is in days.

If concrete is perfectly restrained against deformation $(\Delta \varepsilon=0)$, Eq. (2) and (4) give $\sigma=-E^{\prime \prime} \Delta \varepsilon^{\prime \prime}=-E^{\prime \prime} \varepsilon_{s h}$ or:

$$
\sigma(t) / E\left(t_{o}\right)=\varepsilon_{s h}(t) /\left[1+\chi\left(t, t_{o}\right) \phi\left(t, t_{o}\right)\right]
$$

Consider now the internal force $X(t)$ in a statically indeterminate structure (e.g., the midspan bending moment in a portal frame). If the structure is homogeneous, the ratio $X(t) / X^{e l}{ }_{S}$ defined in the Appendix must equal $\sigma(t) / E\left(t_{o}\right)$ and is thus also given by Eq. (11). For $t-t_{o}=1000$ days and $\phi(\infty, 7)=2.5$, Eq. (9) provides:

$$
\phi\left(t, t_{o}\right)=2.5 \times 63 /(10+63)=2.16
$$

Plotting the values $\chi=0.795,0.956$, and 0.985 for $t_{o}=10,100$, and 1000 days from Table 1 against $\log t_{o}$ and passing a smooth curve through these

TABLE 2 - RATIO IN STRESS RELAXATION ( $\varepsilon=$ CONSTANT) OF STRESS AT $t-t_{o}=10,000$ DAYS AFTER STRAIN INTRODUCTION TO INITIAL STRESS. CREEP LAW GIVEN BY Eq. (7) AND (9) WITH $\phi(\infty, 7)=2.35$

\begin{tabular}{l|c|c|c|c}
\hline \multirow{2}{*}{ Method } & \multicolumn{3}{|c}{ Age $t_{o}$ at strain introduction, days } \\
\cline { 2 - 5 } & $10^{1}$ & $10^{2}$ & $10^{3}$ & $10^{4}$ \\
\hline Exact computer solution & 0.179 & 0.343 & 0.425 & 0.496 \\
Present method using Table 1 & 0.179 & 0.343 & 0.425 & 0.496 \\
Effective modulus method & 0.304 & 0.365 & 0.429 & 0.497 \\
Rate of creep method & 0.100 & 0.173 & 0.262 & 0.361 \\
\hline
\end{tabular}


points, the estimate $\phi\left(t, t_{o}\right)=0.75$ for $t_{o}=7$ days can be made. Eq. (10) gives:

$$
\varepsilon_{8 h}=8 \times 10^{6} \times 1000 /(35+1000)=0.000773
$$

Assuming, for example, that the elastic analysis yielded the value $X^{e l}{ }_{s}=130 \times 10^{8} \mathrm{ft}-1 \mathrm{~b}\left(18 \times 10^{8}\right.$ kgf-m), application of the ratio given by Eq. (11) yields:

$$
\begin{aligned}
X(t) & =130 \times 10^{8} \times 0.000773 /[1+0.75 \times 2.16] \\
& =384 \times 10^{4} \mathrm{ft}-\mathrm{lb}(532,000 \mathrm{kgf}-\mathrm{m})
\end{aligned}
$$

Comparison of the theoretically exact computer solution (obtained by numerical integration of the integral equation of the problem) with the present method and other simplified methods, as well as the effect of variation of $E$, is shown in Fig. 2. The present method is clearly the most accurate one.

As another example, consider the prediction of stress relaxation under constant strain introduced at age $t_{o}$. Substitution of Eq. (3) and (4) with $\varepsilon^{o}=0$ into Eq. (2) with $\Delta \varepsilon=0$ yields:

$$
\sigma(t)-\sigma\left(t_{o}\right)=-E^{\prime \prime} \sigma\left(t_{t}\right) \phi / E
$$
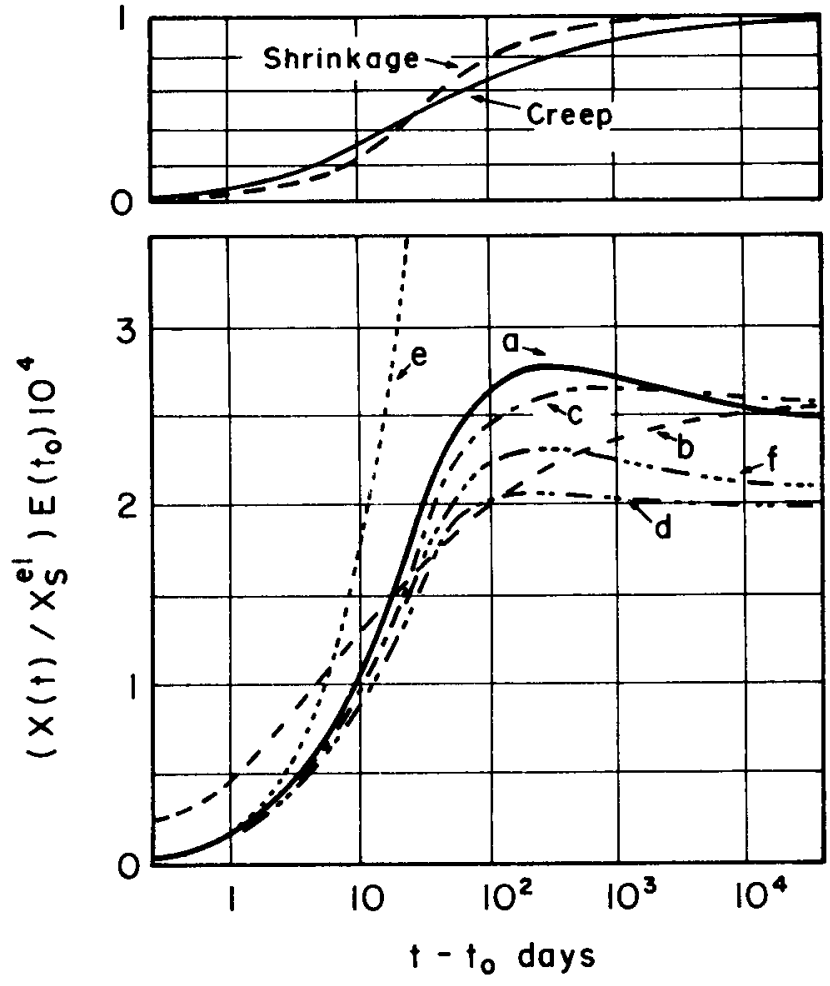

Fig. 2 - Relative values of shrinkage induced force in a homogeneous statically indeterminate structure computed according to shrinkage function Eq. $(10)$ and creep properties given by Eq. (7) and (9) with $\phi(\infty, 7)$ $=2.35$. Curve a denotes theoretically exact computer solution; curve $b$ denotes solution by present method if $\varepsilon_{s h}(t)$ is considered proportional to $\phi\left(t, t_{0}\right)$ with the same final value as from Eq. (10); curve $c$ is for present method, Eq. (II); curve $d$ is for effective modulus method; curve $e$ is for rate-of-creep method with variable $E$; and curve $f$ denotes exact computer solution when variation of $E$ is neglected. Diagram on top gives comparison of shapes of creep curve and unrestrained shrinkage curve according to Eq. $(10)$; for identical shapes, present method would be exact.
After substitution of Eq. (5):

$$
\frac{\sigma(t)}{\sigma\left(t_{o}\right)}=1-\frac{\phi\left(t, t_{o}\right)}{1+\chi\left(t, t_{o}\right) \phi\left(t, t_{o}\right)}
$$

According to the effective modulus method, the ratio $1 /\left[1+\phi\left(t, t_{o}\right)\right]$ is obtained instead of Eq. (12). For the rate-of-creep method, the above ratio is $e^{-\phi\left(t, t_{0}\right)}$. In Table 2, the prediction of these formulas is compared with the theoretically exact solution. Clear superiority of the present method is apparent. (It should be noted that the ratio in Eq. (12) determines the reduction by creep of the effects of any support movement or an introduction of any additional constraints restricting creep deformation in structures of homogeneous creep properties.)

Other examples can be found in References 1 through 5 , in which, however, the constant $E$ should be replaced with the variable $E(t)$.

\section{CONCLUSIONS}

1. The age-adjusted effective modulus is theoretically exact for any creep problem in which strain varies linearly with creep coefficient, instant strain increment at the time of first loading being admissible [Eq. (1) ].

2. The theoretical accuracy of the method presented appears to be distinctly superior to that of the usual effective modulus method, while in simplicity both methods are equal. The method is also much more accurate than the rate-of-creep method.

3. The method is extended for an unbounded final value of creep and also for the variation of elastic modulus whose omission is found to be responsible for a significant error, offsetting the gain in theoretical accuracy.

4. A method of exact determination of the aging coefficient is presented and a table of its values for two typical creep functions is given (Table 1). These values differ considerably from those determined by an approximate analysis in previous publications.

\section{ACKNOWLEDGMENT}

The results presented herein have been obtained in connection with the project sponsored by the National Science Foundation Grant No. GK-26030.

\section{REFERENCES}

1. Trost, H., "Implications of the Superposition Principle in Creep and Relaxation Problems for Concrete and Prestressed Concrete," Beton-und Stahlbetonbau (Berlin-Wilmersdorf), No. 10, 1967, pp. 230-238, 261-269. (in German)

2. ACI Committee 209, Subcommittee 2, "Prediction of Creep, Shrinkage, and Temperature Effects in Concrete Structures," Designing for Effects of Creep, Shrinkage, and Temperature in Concrete Structures, SP-27, American Concrete Institute, Detroit, 1971, pp. 51-93.

3. Trost, H., and Wolff, H. J., "On Realistic Determination of Stresses in Prestressed Concrete Structures 
Built by Segments," Der Bauingenieur (Berlin Wi mersdorf), V. 45, May 1970, pp. 155-179. (in German)

4. Dilger, W., and Neville, A. M., "Verification and Application of a New Method of Creep Analysis to Structural Members," Proceedings, Symposium on Design of Concrete Structures for Creep, Shrinkage, and Temperature Changes (Madrid, Sept. 1970), International Association for Bridge and Structural Engineering, Zurich, 1970, pp. 253-260.

5. Neville, A. M., and Dilger, W., Creep of Concrete; Plain, Reinforced, and Prestressed, North Holland Publishing Co., Amsterdam, 1970, Chapters 17 to 20.

6. Bazant, Z. P., "Numerical Determination of LongRange Stress History from Strain History in Concrete", Materials and Structures, (Paris), V. 5, Apr.-May 1972.

\section{Notation}

\section{APPENDIX}

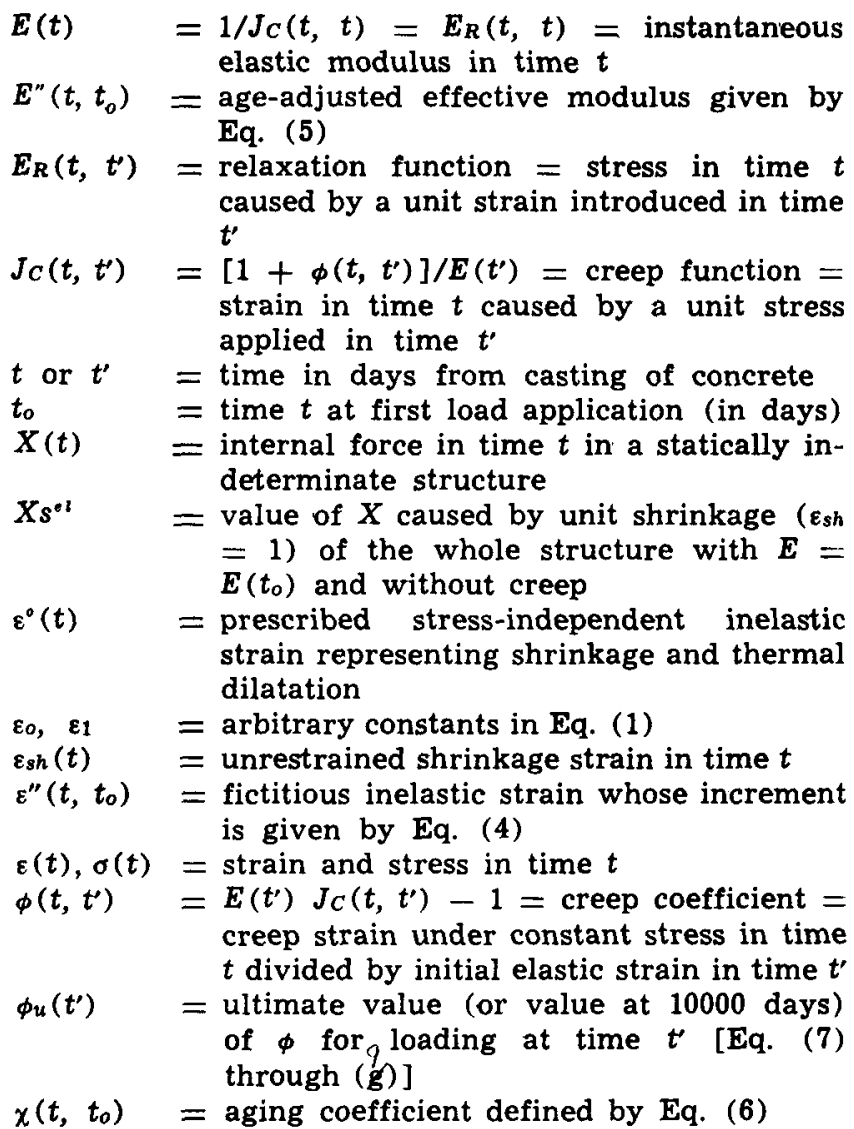

\section{Proof of basic theorem}

The uniaxial creep law may be expressed in either of the following two equivalent forms:

$$
\begin{gathered}
\varepsilon(t)-\varepsilon^{0}(t)=\int_{0}^{t} J_{c}\left(t, t^{\prime}\right) d \sigma\left(t^{\prime}\right) \\
\sigma(t)=\int_{0}^{t} E_{R}\left(t, t^{\prime}\right)\left[d \varepsilon\left(t^{\prime}\right)-d \varepsilon^{0}\left(t^{\prime}\right)\right]
\end{gathered}
$$

in which the integrals must be understood as Stieltjes integrals.

The relation between functions $J_{C}$ and $E_{R}$ may be obtained, e.g., by considering the strain history to be a unit step function, that is, $\varepsilon=1$ for $t \geqslant t_{0}$ and $\varepsilon=0$ for $t<t_{0}$, in which case the stress response is, by definition, $\sigma(t)=E_{R}\left(t, t_{0}\right)$.

Substitution in Eq. (A1) with $\varepsilon^{0}=0$ thus yields:

$$
J_{C}\left(t, t_{0}\right) E\left(t_{0}\right)+
$$

$$
\int_{t_{0}{ }^{+}}^{t} J_{C}\left(t, t^{\prime}\right) \frac{\partial E_{R}\left(t^{\prime}, t_{o}\right)}{\partial t^{\prime}} d t^{\prime}=1
$$

for $t>t_{0}$.

Combination of Eq. (5) and (6) with the relation:

$$
\varphi\left(t, t^{\prime}\right)=E\left(t^{\prime}\right) J_{C}\left(t, t^{\prime}\right)-1
$$

gives:

$$
E^{\prime \prime}\left(t, t_{0}\right)=\left[E\left(t_{0}\right)-E_{R}\left(t, t_{0}\right)\right] / \varphi\left(t, t_{0}\right)
$$

If one substitutes this relation with Eq. (1), (3), and (4) in Eq. (2) and notes that $\sigma\left(t_{0}\right) / E\left(t_{0}\right)=\varepsilon_{o}$, Eq. (2) becomes:

$$
\sigma(t)=\sigma\left(t_{0}\right)+\left[E\left(t_{0}\right)-E_{R}\left(t, t_{0}\right)\right]\left[\varepsilon_{1}-\varepsilon_{0}\right]
$$

for $t \geqslant t_{0}$.

Insertion of this expression and Eq. (1) into Eq. (A1) yields:

$$
\begin{gathered}
\varepsilon_{o}+\varepsilon_{1}\left[E\left(t_{o}\right) J_{C}\left(t, t_{o}\right)-1\right]=J_{C}\left(t, t_{o}\right) \sigma\left(t_{o}\right)- \\
\left(\varepsilon_{1}-\varepsilon_{o}\right) \int_{t_{0^{+}}}^{J^{\prime}} J_{C}\left(t, t^{\prime}\right) \frac{\partial E_{R}\left(t^{\prime}, t_{o}\right)}{\partial t^{\prime}} d t^{\prime}
\end{gathered}
$$

or

$$
\begin{aligned}
\varepsilon_{o}-\varepsilon_{1}=E\left(t_{0}\right) J_{C}\left(t, t_{o}\right)\left(\varepsilon_{o}-\varepsilon_{1}\right)+ \\
\left(\varepsilon_{o}-\varepsilon_{1}\right) \int_{t_{0}+}^{t} J_{C}\left(t, t^{\prime}\right) \frac{\partial E_{R}\left(t, t^{\prime}\right)}{\partial t^{\prime}} d t^{\prime}
\end{aligned}
$$

If $\varepsilon_{o}=\varepsilon_{1}$, this equation is identically satisfied, and if $\varepsilon_{0} \neq \varepsilon_{1}$, Eq. (A6) may be divided by $\left(\varepsilon_{o}-\varepsilon_{1}\right)$ which yields identity Eq. (A3). Noting that a backward transformation from Eq. (A3) through $\mathrm{Eq}$. (A6) and (A5) to Eq. (2) through (6) is also possible, Eq. (2) through (6) are shown to be correct and exact for any $\varepsilon_{0}$ and $\varepsilon_{1}$.

\section{Computation of aging coefficient}

Determination of $\chi$ requires the stress relaxation function to be determined from the given creep function. This can be done by solving Volterra's integral Eq. (A3), which is best carried out numerically. For this purpose, time $t$ may be subdivided by discrete times $t_{1}, \ldots t_{n}$ into $n$ time steps $\Delta t_{r}=t_{r}-t_{r-1}(r=2,3, \ldots n)$; one conveniently puts $t_{0}=t_{1}$, expressing the fact that the first load increment is instantaneous, $t_{1}=0$. If the integral in Eq. (A3) is approximated by a finite sum with the help of the trapezoidal rule, then, after subtracting the forms of Eq. (A3) for $t=t_{r}$ and $t=t_{r-1}$, the following recurrent equation (whose error order is a $\Delta t^{2}$ ) for the increments $\Delta E_{R_{r}}=E_{R}\left(t_{r}, t_{o}\right)-E_{R}\left(t_{r-1}, t_{o}\right)$ is obtained:

$$
\begin{gathered}
\Delta E_{R_{r}}=-2\left(J C_{r, r}+J C_{r, r-1}\right)-1 \times \\
\sum_{8=1}^{r-1} 1 / 2 \Delta E_{R_{s}}\left(J_{C_{r, s}}+J C_{r, s-1}-J C_{r-1,8}-J C_{r-1,8-1}\right) \\
(r=2,3,4, \ldots)
\end{gathered}
$$

where $J_{C_{r, 8}}=J_{C}\left(t_{r}, t_{s}\right)$ and the starting value is $E_{R_{1}}=E\left(t_{o}\right)$.

Computation of the relaxation function and the aging coefficient from this equation and Eq. (6) is a simple task and may be programmed with only a few FORTRAN statements. The time steps $\Delta t_{r}$ are best chosen as increasing in a constant ratio, such as $\Delta t_{r} / \Delta t_{r}-1=10^{1 / 16}$. The first time step $\Delta t_{2}$ should not be chosen larger than the value of the elapsed time $t-t_{0}$ for which $\phi\left(t, t_{0}\right)$ equals about 0.01. Accuracy of Eq. (A7) is quite satisfactory and, for a typical creep function of concrete, 
one can obtain results whose first three decimals are exact if the ratio $\Delta t_{r} / \Delta t_{r-1}$ does not exceed the above value. Although for long creep periods, such as 30 years, Eq. (A7) involves rather long sums, the computation time with a computer such as a CDC 6400 is short. (For creep function Eq. (7), computation of all values $E_{R}\left(t_{r}, t_{o}\right)$ for $r=1, \ldots 100$ and one fixed $t_{o}$ requires about 20 sec.)

\section{Multiaxial stress}

In this case, owing to isotropy, the linear creep law may be expressed by one relation between the volumetric components and one relation between the corresponding deviatoric components of stress and strain. Both of these relations are analogous in form to Eq. (A1) or (A2) and are mutually independent. Hence, the basic theorem with Eq. (1) through (6) may be reformulated for volumetric and deviatoric components, obtaining different values of $\chi$ (and $\phi$ ) in each case. Approximately, however, the Poisson ratio in creep is constant and then the creep functions for volumetric and deviatoric creep are both proportional to $J_{C}\left(t, t^{\prime}\right)$.

Then, the fictitious inelastic volumetric and deviatoric strain increments are both equal to the $\phi\left(t, t_{o}\right)$ multiple of the initial elastic strains, and the age-adjusted bulk and shear moduli, analogous to $E^{\prime \prime}$, are:

$$
\left.\begin{array}{l}
K^{\prime \prime}\left(t, t_{o}\right)=\frac{K\left(t_{o}\right)}{1+\chi\left(t, t_{o}\right) \phi\left(t, t_{o}\right)} \\
G^{\prime \prime}\left(t, t_{o}\right)=\frac{G\left(t_{o}\right)}{1+\chi\left(t, t_{o}\right) \phi\left(t, t_{o}\right)}
\end{array}\right\}
$$

where $K$ and $G$ are the actual instantaneous bulk and shear moduli.

This paper was received by the Institute May 20, 1971. 